\title{
Assessment of Rainfall Variations in South Region, Cameroon
}

\author{
Severin Mbog Mbog1, Bill Vaneck Bot ${ }^{2,3^{*}}$, Olivier T. Sosso ${ }^{3}$, Lizzette Nsobih ${ }^{4}$, \\ Dieudonne Bitondo ${ }^{1,2}$
}

\author{
${ }^{1}$ Department of Industrial Quality, Hygiene, Industrial Safety and Environment Engineering, National Advanced School for \\ Engineering, University of Douala, Douala, Cameroon \\ ${ }^{2}$ Laboratory of Thermal and Environment, Advanced Teacher's Training College for Technical Education, University of \\ Douala, Douala, Cameroon \\ ${ }^{3}$ Laboratory of Energy, Materials, Modeling and Methods, National Advanced School for Engineering, University of \\ Douala, Douala, Cameroon \\ ${ }^{4}$ Faculty of Agriculture and Veterinary Medicine, University of Buea, Buea, Cameroun \\ Email: ^bbillvaneck@yahoo.fr
}

How to cite this paper: Mbog Mbog, S. Bot, B. V., Sosso, O. T., Nsobih, L., \& Bitondo, D. (2020). Assessment of Rainfall Variations in South Region, Cameroon. American Journal of Climate Change, 9, 410-422.

https://doi.org/10.4236/ajcc.2020.94026

Received: August 1, 2020

Accepted: December 19, 2020

Published: December 22, 2020

Copyright $\odot 2020$ by author(s) and Scientific Research Publishing Inc. This work is licensed under the Creative Commons Attribution International License (CC BY 4.0).

http://creativecommons.org/licenses/by/4.0/

(c) (i) Open Access

\begin{abstract}
This study of rainfall variation in the south region of Cameroon has as objective to evaluate the present climate trends in the south region using weather data from 1960 to 2010. To achieve this objective, daily and monthly rainfall data were collected from the Ebolowa weather station. Results of this study show that generally, the south has an average of $1807 \mathrm{~mm}$ of rainfall in an average of 165 days. Two rainfall regimes were recognized, the bimodal with four seasons: two dry and two rainy seasons and occupies $88 \%$ of the region climatic system. The trimodal with six seasons three dry and three rainy seasons and occupies $22 \%$ of the region climatic system. Despite this seasonal repetition, rainfall is experienced in all the months of the year within the 50 years' study period, with constant seasonal displacement and compensation within the seasons. Generally, there is a constant decrease in rainfall and number of days of rainfall but rainfall is decreasing faster than the number of days and the rainfall patterns are more or less irregular.
\end{abstract}

\section{Keywords}

Rainfall, Variations, Bimodal, Trimodal, Season

\section{Introduction}

Climate is the average or typical weather condition observed over a long period 
of time at least 30 years for a given geographical location. By definition climate variation refers to changes in one or more climatic variables (rainfall, temperature, wind etc.) over a specified time (Burtis, 1989) while climate change is the long-term shift in the climate of a specific location, region or planet. This shift is measured by changes in features associated with average weather, such as temperature, wind patterns and precipitation (J. O, 1988). Thus variation in climate actually results in changes in climate. It is now widely accepted that the climate varies and is changing all over the world. The global mean temperature increased by $0.6^{\circ} \mathrm{C}$ in the last century, and the 1990 s were particularly the hottest years (I. C. Change, 2001). On the whole, wetter periods have been succeeded by drier periods and cold periods by hot ones (Peel, 1966). Climate models predict that mean annual global temperature will increase by $1^{\circ} \mathrm{C}-3.5^{\circ} \mathrm{C}$ by 2100 and global mean sea level will rise by $15-95 \mathrm{~cm}$ with changes occurring in the spatial and temporal patterns of precipitation (Burtis, 1989; I. P. on C. Change, 1997).

According to some recent studies, rainfall variations have been perceived in the world and slowly in African countries. Analysis of annual precipitations range features an important change of North African, South Asian, Southern African and Western American in accordance to appreciate study (Zhang \& Zhou, 2011). Africa's emissions of climate change-inducing carbon dioxide are still low, estimated to be only $3.6 \%$ of the world's total. Although Africa has not historically contributed to climate change, and its forests have provided a significant sink for the carbon emitted by industrialized countries, it is predicted that the continent will be the most affected by the adverse effects of climate change, as many aspects of African economies are extremely climate sensitive and they are less able to cope with this impact (I. P. on C. Change, 1997; E. L, 1999).

Average temperatures in Cameroon have been increasing since 1930 (Ayonghe \& Suh, 2001). The net rate of increase has been $0.95^{\circ} \mathrm{C}$ between 1930 and 1995. This increase certainly falls in line with the global trend of $1.5^{\circ} \mathrm{C}$ (C. Change, 1992) which is a link to the modification of the atmosphere with greenhouse gases. Available data indicate increasing trends in the frequency of rainfall days, with decrease in the quantity of rainfall annually. The mean annual rainfall has decreased by $2.9 \mathrm{~mm}$ per month i.e. 2.2\% per decade since 1960, experience particularly in 2003 and 2005. Although the dense rainforest region continues to include some of the wettest places on earth (Lambi, 2001).

A comparison of the years with the highest and lowest rainfalls shows a marked variability. The years with extreme rainfall have a tendency to cluster, thereby indicating extreme dry and wet periods (Beauvilain, 1985). There has been a succession of droughts and floods in the northern part of Cameroon with increasing frequency over time. These floods have always been preceded by a period of drought. However, despite these fluctuations between floods and droughts, climatic data shows that the rainfall over the years has been on the decline in most parts of the country (Ayonghe \& Suh, 2001). The main objective of this work is to contribute to the evaluation of the evolution and typology of rainfall in the south region from 1960 to 2010. 


\section{Materials and Methods}

\subsection{Study Area}

The southern region of Cameroon is located in the southwestern and south-central portion of the Republic of Cameroon. It is located at latitude $02^{\circ} 41^{\prime}$ North and longitude $12^{\circ} 35^{\prime}$ East and is bordered to the east by the East Region, to the north by the Centre Region, to the northwest by the Littoral region, to the west by the Gulf of Guinea (part of the Atlantic Ocean), and to the south by the countries of Equatorial Guinea, Gabon, and Congo. The South covers $47.191 \mathrm{~km}^{2}$ thus takes $5 \%$ of the country's surface area (Figure 1).

\subsection{Data Collection}

The climate data were collected from the Ebolowa weather station. Daily and monthly climate data from the Ebolowa weather station comes from the Metrological headquarters in Douala, which is the main collector of climate data in Cameroon. The climatic data were processed through SPSS because of the large nature of the data.

\subsection{Data Analysis}

Calculating the monthly and annual average rainfall and number of days of rainfall

The average monthly rainfall and number of days of rainfall are obtained from the following equations:

$$
\begin{aligned}
& A R=\Sigma(P x) / N b \\
& E m=\Sigma(N x) / N b
\end{aligned}
$$

where

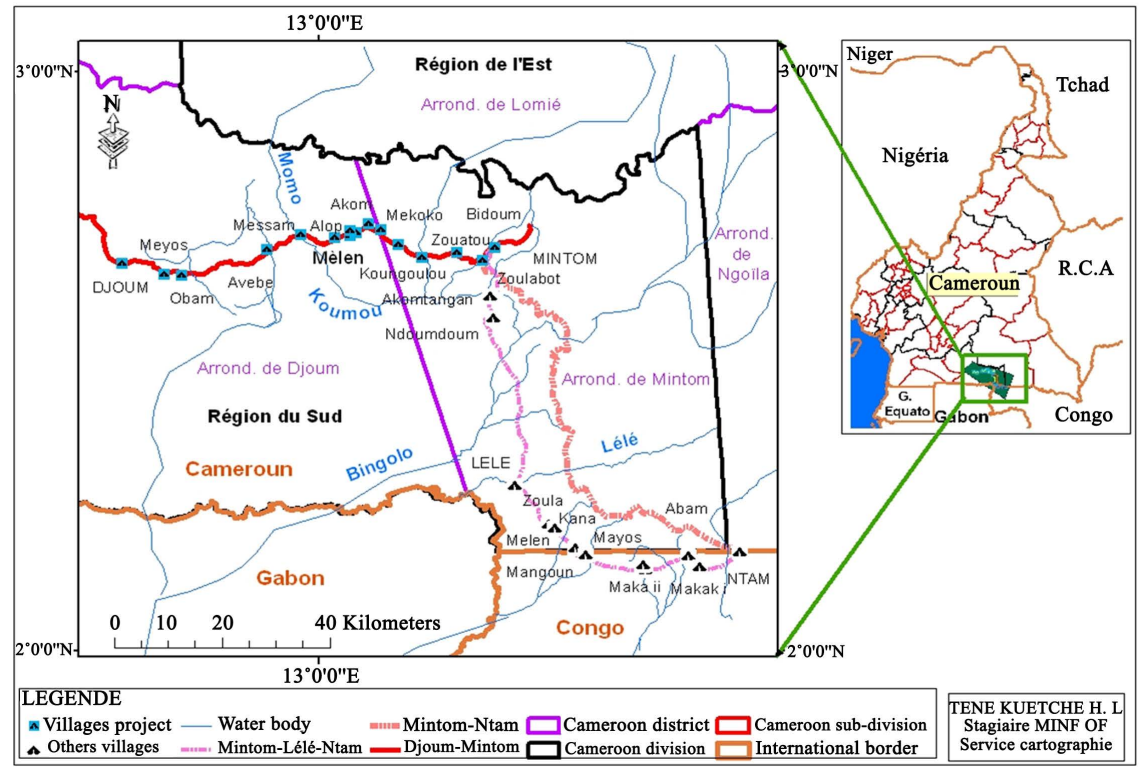

Figure 1. Location of study area. 
$P x=$ monthly volume/annual volume of rainfall collected at the station Ebolowa in mm;

$N b=$ total number of months;

$A R=$ average monthly rainfall/annual rainfall in $\mathrm{mm}$;

$N x=$ number of days of rainfall per year recorded at the Ebolowa station in days;

$\mathrm{Nb}=$ total number of months/year;

$E m=$ number of months/average number of days of rainfall per year, in days.

Calculating the average seasonal rainfall and number of days of rainfall per season

The average seasonal rainfall and the number of days of rainfall during the rainy season are obtained from the following equations:

$$
\begin{aligned}
& S P=\Sigma(P x) / N b \\
& N S=\Sigma(N x) / N b
\end{aligned}
$$

where

$S P=$ seasonal volume of rainfall collected/seasonal number of days of rainfall in $\mathrm{mm}$;

$N b=$ total number of months during the rainy season;

$P x=$ average rainfall per season in $\mathrm{mm}$;

$N x=$ number of seasonal days recorded at the station in days;

$N b=$ total number of months during the season;

$N S=$ number of seasonal rainfall days, in day.

In this study, the dates of the beginning and end of rainfall will be determined using the first day criteria i.e. from the $1^{\text {st }}$ of January 1960 when we register more than $20 \mathrm{~mm}$ of rainfall in 1 or 2 days without a dry episode of more than 7 days in the rest of the month. The dates of the end of rainfall are determined when we register less than $20 \mathrm{~mm}$ of rainfall without any cumulative rainfall (Audroing et al., 1979).

Calculating rainfall variation from the average rainfall and number of days of rainfall

Variation in the average rainfall is calculated based on the following statistical formula:

$$
\begin{gathered}
\operatorname{Eave}(p)=R i-P m \\
\operatorname{Emoy}(N b)=N B R I-N B R M
\end{gathered}
$$

where:

$$
\left\{\begin{array}{l}
\text { Eave }(p)=\text { variation from the average rainfall; } \\
R i=\text { rainfall in a given year in mm; } \\
P m=\text { average rainfall recordedina given time interval; } \\
N B R I=\text { Number of rainfalldaysin a given year; } \\
N B R M=\text { Average number of days of rainfall over a given time interval; } \\
\text { Eave }(N b)=\text { variationfrom the average number of days of rainfall. }
\end{array}\right.
$$

Calculation of the percentage seasonal rainfall at the Ebolowa station

The percentage seasonal rainfall is the sum of the total rain collected per season on the total annual rainfall recorded. 
It is obtained from the following formula:

$$
\% P(\text { season })=\frac{\sum P(\text { season })}{p(\text { total annual })} \times 100
$$

With $P=$ Rainfall in $\mathrm{mm}$.

\section{Results}

The results observed in the field can be grouped into three, the climatic trends of the south region from 1960 to 2010 .

\subsection{Annual Changes in Rainfall during the Dry and Rainy Seasons}

With the exception of the short dry season with increase rainfall in the south region, the long and short rainy seasons and the long dry season shows decrease in rainfall from 1960 to 2010 (Figure 2).

The long and short rainy seasons are the wettest in the south region. The short rainy season which lasts one month longer than the long rainy season records 49 $\mathrm{mm}$ of rainfall more than the long season $718 \mathrm{~mm}$.

The evolution of rainfall in the long and short rainy seasons shows two phases within the 50 years of study. The first which is the wettest from 1960 to 1990 . This period recorded $733 \mathrm{~mm}$ of rainfall for the long rainy season and $817 \mathrm{~mm}$ for the short rainy season. The period from 1991 to 2010 which is the driest records $795 \mathrm{~mm}$ of rainfall for the short rainy season and $659 \mathrm{~mm}$ of rainfall for the long rainy season.

The short and long dry seasons have less rainfall since they have less than 20\% of rainfall in the course of the year. The short dry season has $165 \mathrm{~mm}$ records 10 $\mathrm{mm}$ and the long dry season has $155 \mathrm{~mm}$ of rainfall. The changing trends in rainfall over two seasons are controversial. While the short dry season is gradually increasing, the long dry season is decreasing. Rainfall distribution is uneven over the study period. Only the short dry season is increasing, the long rainy season, the long dry season and short dry seasons are in constant decline over the period of study.
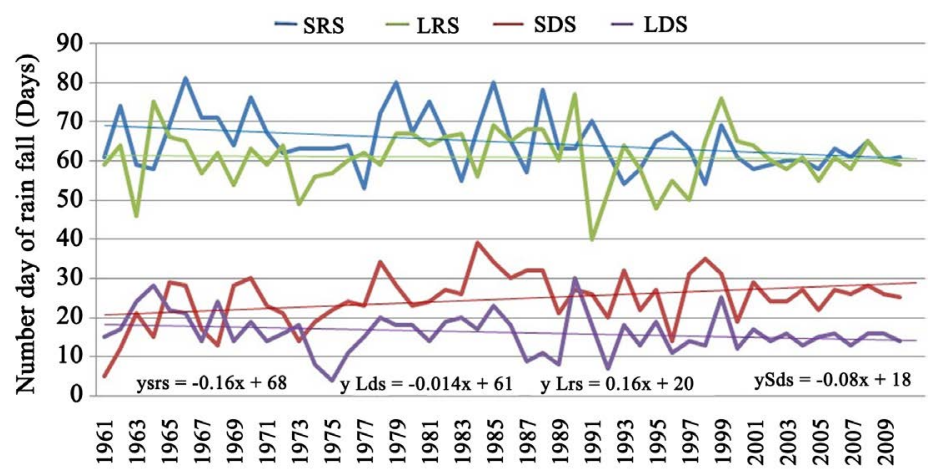

Figure 2. Evolution of annual changes in rainfall during the dry and rainy seasons. (SRS $=$ Small Rainy Season; LRS = Long Rainy Season, LDS = Long Dry Season; SDS = Short Dry Season). 


\subsection{Variation from the Average Rainfall in the South Region during the Dry and Rainy Seasons from 1960 to 2010}

Variation from the average rainfall expresses the difference in the precipitation of a given year and precipitation based on the rainfall series of the study period.

Figure 3 shows the deviations from the average rainfall for the short and long dry seasons, it shows that:

- 20 years of excess rainfall during the long dry season and 30 years of deficit;

- 25years excess rainfall during the short dry season and 25 years' deficit.

We can conclude that in each five years of the fifty years of observation, we observe 02 cases of compensation between the two long excess dry season and 03 cases of compensation between the two long deficit dry seasons. For the short dry season, a compensation case is observed in every two years between a short excess dry season and the long deficit dry season. Figure 4 shows variation from the mean between the short and the long rainy season of the study period. We note here that:

- 23 years of excess during the long rainy season, whereas 27 years are in deficit;

- 24 years of excess during the short rainy season, whereas 26 years are in deficit.

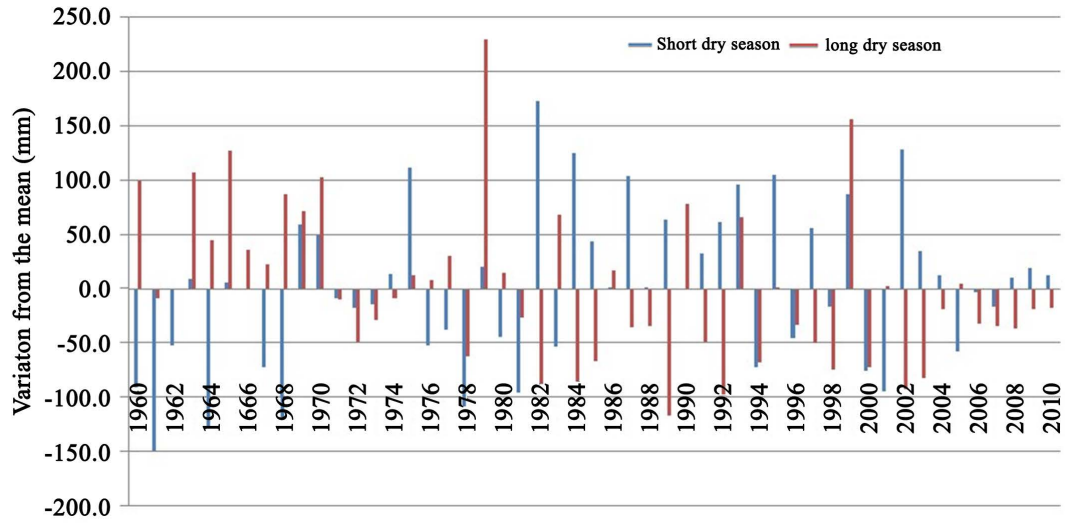

Figure 3. Variation from the average rainfall in the South region during the dry seasons.

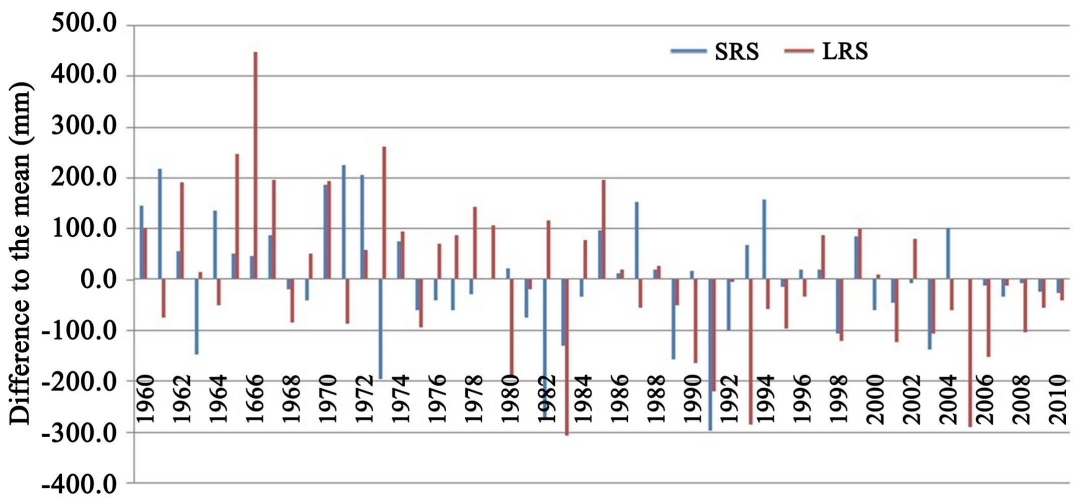

Figure 4. Variation from the average rainfall in the south region during rainy seasons over the study period. 
The result shows that in every five years in the fifty years of study, 2.3 cases of compensation can be observed between a long excess rainy season and 2.7 cases of compensation between the long deficit rainy seasons. For the short rainy season, in every five years, 2.4 cases of compensation are observed between the short excess rainy season and 2.6 cases of compensation between a short deficit rainy season.

\subsection{Variation from the Average Number of Days of Rainfall in the South Region during the Dry and Rainy Seasons over the Study Period}

Variation from the average number of days of rainfall is the annual rainfall information, that determines the difference in the number of rainfall days in a given year and the number of days of rainfall calculated on the rainfall series in the study period.

Figure 5 shows that:

- 20 years of excess and 30 years of deficit in the number of days of rainfall during the short rainy season;

- 25 years of excess and 25 years are deficit in the number of days of rainfall during the long rainy season.

Figure 6 shows the evolution of the number of days of rainfall during the small and long dry season in south region over the study period. It appears here that:

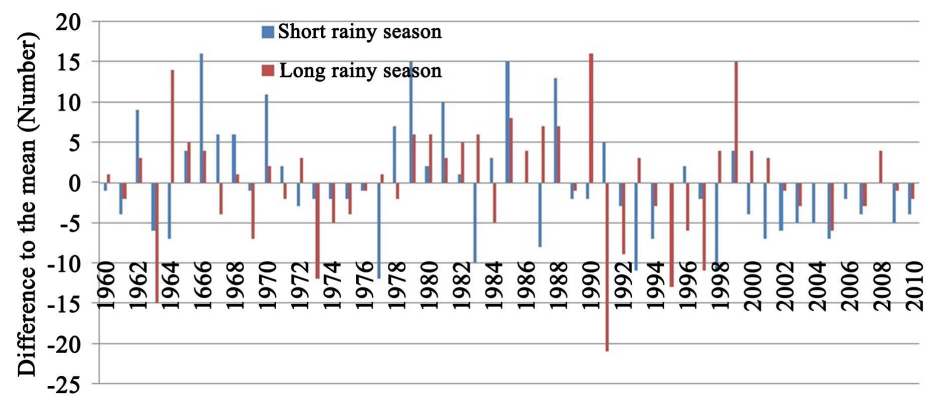

Figure 5. Variation from the average number of days of rainfall in the south region during rainy seasons over the study period.

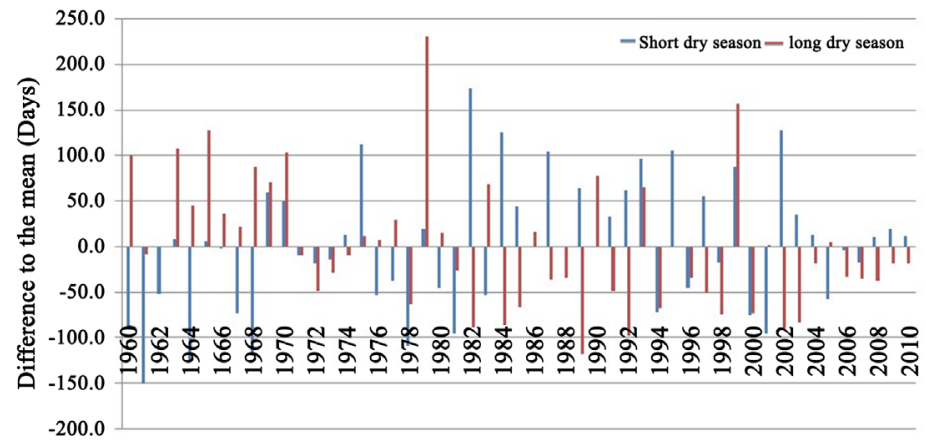

Figure 6. Variation from the average number of days of rainfall in the south region during dry seasons over the study period. 
- 26 years of excess and 24 years of deficit during the short dry season;

- 25 years of excess and 25 years of deficit during the long dry season.

The evolution of the number of days of rainfall during the short and long rainy season shows that it is possible to have 02 cases in 05 a small excess number of days of rainfall and 03 cases in 05 a small deficit in the number of days of rainfall. For the long dry season, we observed in every two years a case of compensation in the number of days of rainfall between the long excess rainy season and a long deficit rainy season. Following the evolution of the number of days of rainfall during the short and long dry season, its shows that it is possible to have 03 in 05 cases a small excess number of days of rainfall for the short dry season and 02 in 05 cases a small deficit in the number of days of rainfall. For the long dry season, we observed in every two years a case of compensation in the number of days of rainfall between along excess dry season and a long deficit dry season.

\subsection{Evolution of the Average Annual Rainfall Patterns in Ebolowa Station over the Study Period}

As shown in Figure 7, there is a progressive decrease in rainfall and number of rainfall days in the south region over the study period.

It rains $1807 \mathrm{~mm}$ per year over 165 days on average. The year 1970, which recorded $2338 \mathrm{~mm}$ of rainfall, is the wettest, while the year 1991 records only $1272 \mathrm{~mm}$ of rainfall is the least. Changing trends shows two distinct phases. The wettest between 1960 and 1990 with $1878 \mathrm{~mm}$ recording $182 \mathrm{~mm}$ more than the period 1991-2010 per year. From 1960 to 2010, the wettest years are not always the most spread. The year 1985, which is spread over 206 days, recorded 2075 $\mathrm{mm}$ of rainfall, and the year 1992 which is the least spread with 172 days recorded $1533 \mathrm{~mm}$ of rainfall. In general, rainfall and number of days of rainfall decrease gradually over this 50 years' study. Rainfall decreases slightly faster than the number of days of rainfall recorded. This significant difference between the two rainfall variables shows an enormous decrease in the quantity of rainfall with time. Such heavy rains often generating natural disasters.

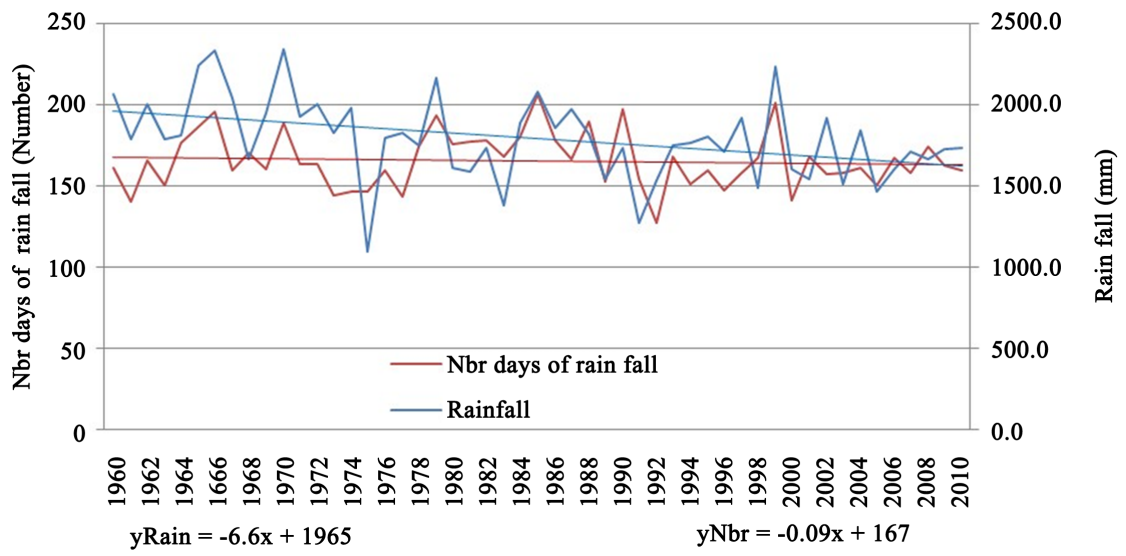

Figure 7. Average annual precipitation and number of rainfall days in the South region. 


\subsection{Typology of Rainfall in the South Region from 1960 to 2010}

Two rainfall regimes are identified in the south over the study period. We have the bimodal which is the majority and the trimodal the minority.

\section{Regime distribution observed in the south region}

The distribution of rainfall patterns observed in south region Table 1 shows that the majority is the bimodal with $88 \%$, followed by trimodal system that represents only $12 \%$ of the identified regime.

\section{The bimodal regime in the south region over the study period}

In general, the short rainy season lasts for 03 to 04 months and records $42.3 \%$ of the total annual rainfall. While the long rainy season that does not exceed 03 months has only $40 \%$ of the annual precipitation. The bimodal regime is characterized by two dry seasons and two rainy seasons with variable length. The bimodal is observed during 44 years for the 50 years' data studied; it represents $88 \%$ of the identified regime. The maximum height of rainfall is between September and October (Figure 8).

The total annual rainfall is $1807 \mathrm{~mm}$ on average. The short dry season lasts for 02 months; July-August, while the long dry season that lasts for 03 months runs from December to February. The bimodal regime is specific to the south region over the study period. The average annual rainfall is $1807 \mathrm{~mm}$ distributed within the four seasons, thus two dry and two rainy seasons with variable durations. Rainfall distribution is uneven in the 04 seasons of the year.

Annual changes in rainfall in the trimodal regime in the south region from 1960 to 2010

The trimodal system is observable in 06 years it has 06 seasons thus, three wet and three dry seasons, with varying durations. Figure 9 shows the evolution of the trimodal rainfall regime in the years 1965, 1975 and 1980. Over these years we observed a steady regular displacement of the different seasons within the year. The short dry seasons vary between the months of April, June, and August, while the short rainy seasons occur respectively in the periods of January to March, May-June and July. The long dry season is permanent between the months of November to February, while the long rainy season is observed between September and November. The evolution of rainfall follows the trimodal

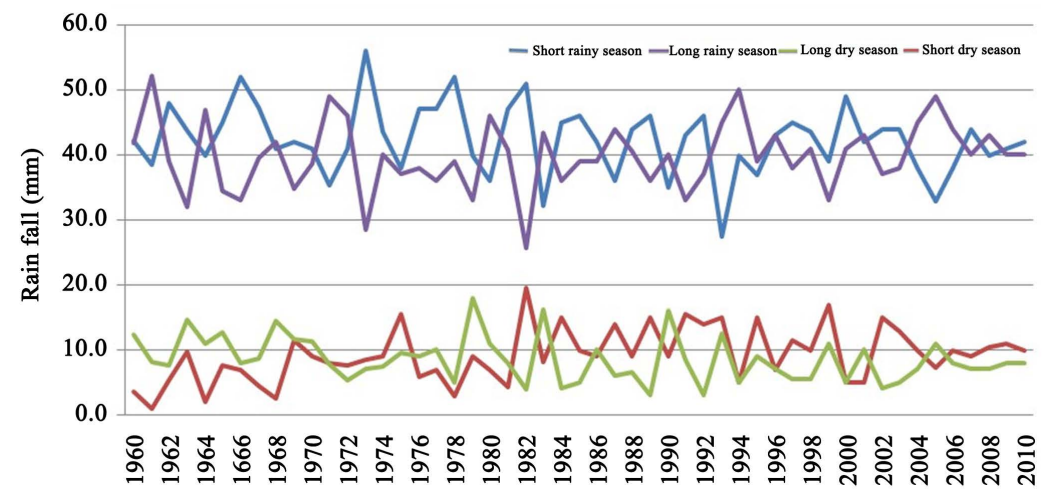

Figure 8. Distribution by season rainfall in the bimodal regime in the south region. 


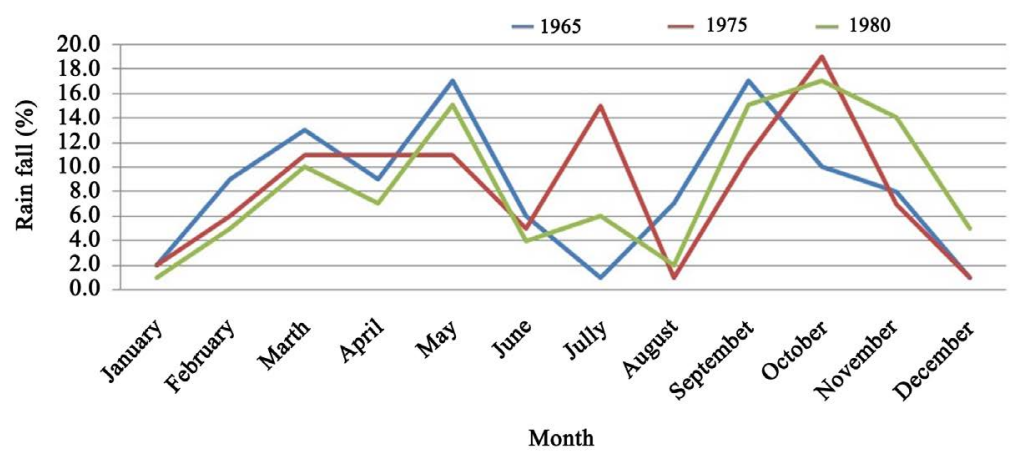

Figure 9. Distribution of rainfall in the trimodal climate regime in 1965, 1975, and 1980.

Table 1. Proportion of years by regime observed in South region.

\begin{tabular}{cccc}
\hline Regime & Bimodal & Trimodal & TOTAL \\
\hline Percentage & $88 \%$ & $12 \%$ & $100 \%$ \\
Years & 45 & 06 & 51 \\
\hline
\end{tabular}

system in the south region in 1982, 1988 and 1995. In the first three years, the dry and rainy seasons remains unstable during the year. The Short dry seasons are constantly being displaced between the months of April, May, July and August during the year. The short rainy seasons on the contrary vary between the periods of February-March, May-June, and August-September. The long dry season on the contrary is displacing between the months of November and February, while the long rainy season differs between August and November (Figure $10)$.

\section{Discussions}

A look at the climatic trend in the south region shows that there is rapid climate variation which is sign of climate change. This in line with (Ayonghe \& Suh, 2001) and (E. L, 1999) who carried out similar studies on climate in Cameroon and concluded that they are variations of season and a decrease in rainfall and number of days of rainfall. But the decrease in rainfall is more rapid than that of number of days of rain.

Rainfall variations in Cameroon's South region can be ascertained by comparison with other African Regions. A study made in Central Equatorial African confirmed a trouble of seasonal cycle (Hua et al., 2019); (Fotso-Nguemo et al., 2017) projected the rainfall amount to decrease by up to $5 \mathrm{~mm}$ per day. The behavior of the variations of precipitation in this region seems to be similar to West African Region with predicted significant climatic change accompanied by long term reduction of rainfall (Nicholson, 2001). Similar phenomena have been identified in Botswana where decreased rainfall throughout the nation, which is associated with decreases in the number of rainy days (Batisani \& Yarnal, 2010). Even in East African countries, a temporal analysis indicated an overall slight decrease in rainfall (Kimani et al., 2017). 


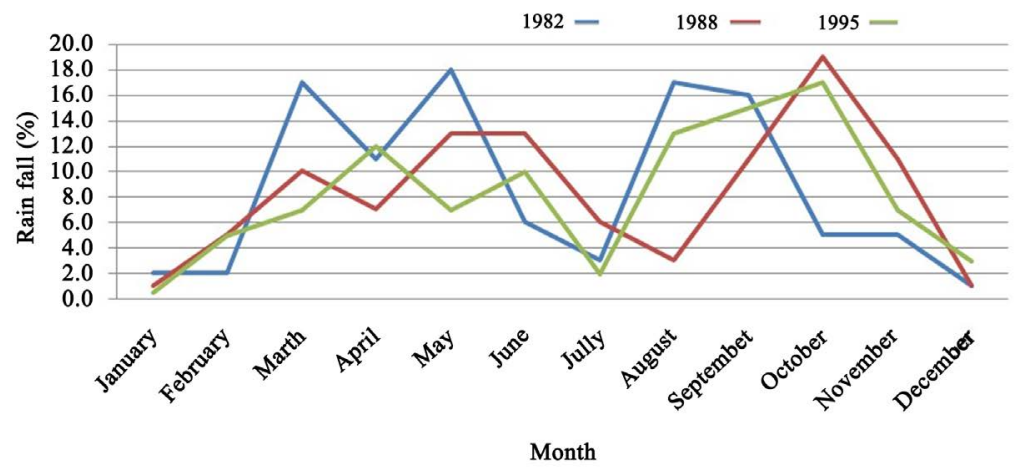

Figure 10. Distribution of season in the trimodal regime in 1982, 1988, and 1995.

The distribution of these seasons and the number of days of rainfall are not regular over the study period. They are constant displacement of seasons as seen in the trimodal regime. The beginnings of late rains do not always coincide with the late endings of rain, as well as the anticipated rainfalls do not always correspond to that collected. Also field investigation shows that the wet periods are accompanied by high temperature days as well as the dry period with rainy days. This in line with (Beauvilain, 1985) and (Peel, 1966) who carried out studies on climate in the north of Cameroon and concluded that extreme dry and wet period turn to cluster together, making it difficult to determine the beginning and end of each season. Beside the displacement of seasons, they are the phenomenon of seasonal compensation where a deficit in rainfall in a season is being compensated for in the preceding season. This phenomenon can be used to predict the next season thought it's a matter of probability and can only be done within a year. This however is very frequent in the dry seasons.

Precipitation is an important climate variable whose long-term changes are of great interest to the society. In Cameroon, rainfall variations have impact on many sectors and activities such as agriculture, economy, hydropower, forest management and agriculture (Bele et al., 2011; Grijsen, 2014; Laux et al., 2010; Molua, 2007, 2009). Faced with these impacts, proposals for adaptive measures are made, as shown by some works which studied adaptation in order to compensate impacts of climate change on Cameroonian's agriculture (Tingem et al., 2009; Tingem \& Rivington, 2009).

\section{Conclusion}

The south region shows a constant variation of seasons with two climate regime alternating year after year. Beside the two climatic regimes observed it's clear that they are four seasons, though the trimodal regime shows six seasons, experienced in six years within the fifty years' study. These seasons are constantly being displaced with the compensation of one season for other. The long and short dry seasons have three and two months respectively with $20 \%$ rainfall while the rainy periods have seven to eight months. From field observation, the rainy seasons are interwoven with high temperature days as well as the dry seasons are accompanied with rainfall, thus making it difficult to have an actual 
prediction of the future. Beside the differentiation in seasons, there is no month without rainfall in the region and the regular displacement of one season to the other makes it difficult to predict with certainty the beginnings and ends of seasons within the year. The south like most regions in Cameroon is experiencing rapid climate variations which are signs of climate variation.

\section{Conflicts of Interest}

The authors declare no conflicts of interest regarding the publication of this paper

\section{References}

Audroing, J.-F., Abboud, N. et al. (1979). Initiation au calcul des probabilités et à la théorie de l'échantillonnage.

Ayonghe, S. N., \& Suh, C. E. (2001). A Quantitative Evaluation of Global Warming and Precipitation in Cameroon from 1930 to 1995 and Projections to 2060: Effects on Environment and Water Resources. Reading in Geography, 14, 142-155.

Batisani, N., \& Yarnal, B. (2010). Rainfall Variability and Trends in Semi-Arid Botswana: Implications for Climate Change Adaptation Policy. Applied Geography, 30, 483-489. https://doi.org/10.1016/j.apgeog.2009.10.007

Beauvilain, A. (1985). Remarques sur la situation pluviometrique actuelle au Nord Cameroun. Cameroon Geographical Review, 5, 47-61.

Bele, M. Y., Somorin, O., Sonwa, D. J., Nkem, J. N., \& Locatelli, B. (2011). Forests and Climate Change Adaptation Policies in Cameroon. Mitigation and Adaptation Strategies for Global Change, 16, 369-385. https://doi.org/10.1007/s11027-010-9264-8

Burtis, M. D. (1989). Carbon Dioxide Information Analysis Center Catalog of Data Bases and Reports (Issue 3477). Oak Ridge National Laboratory.

C. Change (1992). The Supplementary Report to the IPCC Scientific Assessment. Cambridge: Cambridge Univ. Press.

E. L, M. (1999). Economic Optimization of Smallholder Agro Forestry Systems in SouthWestern Cameroon. Copenhagen: University Copenhagen.

Fotso-Nguemo, T. C., Vondou, D. A., Tchawoua, C., \& Haensler, A. (2017). Assessment of Simulated Rainfall and Temperature from the Regional Climate Model REMO and Future Changes over Central Africa. Climate Dynamics, 48, 3685-3705. https://doi.org/10.1007/s00382-016-3294-1

Grijsen, J. (2014). Understanding the Impact of Climate Change on Hydropower: The Case of Cameroon.

Hua, W., Zhou, L., Nicholson, S. E., Chen, H., \& Qin, M. (2019). Assessing Reanalysis Data for Understanding Rainfall Climatology and Variability over Central Equatorial Africa. Climate Dynamics, 53, 651-669. https://doi.org/10.1007/s00382-018-04604-0

I. C. Change (2001). The Scientific Basis (Report of Working Group I of the Intergovernmental Panel on Climate Change, IPCC Secretariat, Geneva, 2001).

I. P. on C. Change (1997). The Regional Impact of Climate Change: An Assessment of Vulnerability.

J. O, A. (1988). Introduction to Climatology for the Tropics (p. 312). Bloomington, IN: Indiana University Press.

Kimani, M. W., Hoedjes, J. C. B., \& Su, Z. (2017). An Assessment of Satellite-Derived 
Rainfall Products Relative to Ground Observations over East Africa. Remote Sensing, 9, 430. https://doi.org/10.3390/rs9050430

Lambi, C. M. (2001). The Impact of Human Activity on Land Degradation in Some Highland Regions of Cameroon: Implications for Development. In Environmental Issues: Problems and Prospects (pp. 45-66). Bamenda: Unique Printers.

Laux, P., Jäckel, G., Tingem, R. M., \& Kunstmann, H. (2010). Impact of Climate Change on Agricultural Productivity under Rainfed Conditions in Cameroon-A Method to Improve Attainable Crop Yields by Planting Date Adaptations. Agricultural and Forest Meteorology, 150, 1258-1271. https://doi.org/10.1016/j.agrformet.2010.05.008

Molua, E. L. (2007). The Economic Impact of Climate Change on Agriculture in Cameroon. World Bank Policy Research Working Paper Series. https://doi.org/10.1596/1813-9450-4364

Molua, E. L. (2009). An Empirical Assessment of the Impact of Climate Change on Smallholder Agriculture in Cameroon. Global and Planetary Change, 67, 205-208. https://doi.org/10.1016/j.gloplacha.2009.02.006

Nicholson, S. E. (2001). Climatic and Environmental Change in Africa during the Last Two Centuries. Climate Research, 17, 123-144. https://doi.org/10.3354/cr017123

Peel, R. F. (1966). The Landscape in Aridity: Presidential Address. Transactions of the Institute of British Geographers, 38, 1-23. https://doi.org/10.2307/621421

Tingem, M., \& Rivington, M. (2009). Adaptation for Crop Agriculture to Climate Change in Cameroon: Turning on the Heat. Mitigation and Adaptation Strategies for Global Change, 14, 153-168. https://doi.org/10.1007/s11027-008-9156-3

Tingem, M., Rivington, M., \& Bellocchi, G. (2009). Adaptation Assessments for Crop Production in Response to Climate Change in Cameroon. Agronomy for Sustainable Development, 29, 247-256. https://doi.org/10.1051/agro:2008053

Zhang, L., \& Zhou, T. (2011). An Assessment of Monsoon Precipitation Changes during 1901-2001. Climate Dynamics, 37, 279-296. https://doi.org/10.1007/s00382-011-0993-5 